\title{
Analysis and assasment method of the Chirchik river flow for water supply and water use
}

\author{
Dildora Makhmudova*, and Hurshid Makhmudov \\ ${ }^{1}$ Tashkent institute of architecture and civil engineering, Tashkent, Uzbekistan
}

\begin{abstract}
The scientific work is devoted to studying hydroecological problems and methods for assessing the transformation of river water on the example of the Chirchik River, which flows through large industrial centers of the Republic of Uzbekistan and the territory of its capital, Tashkent. Investigations of quantitative and qualitative transformation of river water runoff were carried out using the interpolation method. The main task is to describe the method of interpolation of hydrometeorological data of the territories; For such system, the center in this work adopted a material point that characterizes the movement of the whole system; for this research, such as the hydrometeorological parameters of the territory. The data of the hydrometeorological service of the Republic of Uzbekistan were used when interpolating climatic parameters, which are the main determining factors in the formation and transformation of the river flow of Chirchik. In the proposed interpolation method, a combined system is created, consisting of a landscape-natural component, a system representing a moving mass with a single center. The meteorological parameters of the territory are taken as elements of the mass system, which have their centers of change-movement. The performed test calculations showed that the difference in meteorological parameters affects the position of their centers; each parameter: atmospheric pressure, precipitation, humidity, and temperature, etc., has its center.
\end{abstract}

\section{Introduction}

The rivers of Uzbekistan, especially the Chirchik River and its resources for many millennia, have been a source of water supply for the population. Now it has great importance for the economy of Tashkent region.

However, in the middle of the 20th and the beginning of the 21 st century, the Chirchik river ecosystem is susceptible to serious man-made impacts: complete depletion of the river's resources, the transformation of its channel in the middle and lower reaches into a source of non-metallic materials, which determines the critical state of the use of its water resources of rivers for drinking water supply to the population and the ecological state of the territories adjacent to the river basin.

The rapidly developing branch of the water economy of the Tashkent oasis is the water supply of industrial facilities, cities, and towns. The main water supply facilities are Tashkent-Chirchik, Angren, Almalyk-Akhangaran and Bekabad industrial regions. The

*Corresponding author: dildoram76@mail.ru 
largest consumers of water and thermal power plants, factories of ferrous and nonferrous metallurgy, enterprises of the oil refining and petrochemical industries, cotton ginning, and bast enterprises. Together with water use and water consumption of river water, large industrial enterprises and public water supply facilities are sources of pollution of river water and the river bed, which determines the relevance and necessity of researching the hydroecological problems of the Chirchik river basin.

\section{Materials and Methods}

The object of research is the territory of the Chirchik river basin in the Republic of Uzbekistan. To monitor hydrometeorological factors, four hydrometeorological stations have been installed and operate on this territory

The choice of the location of hydrometeorological stations on the territory of the Chirchik river basin is determined from the climatic and zonal conditions of the territory. Tashkent's hydrometeorological station is located in the center of Tashkent city and is naturally under significant influence of anthropogenic factors. The Chimgan hydrometeorological station is located in the mountainous part of the basin, where anthropogenic factors do not significantly affect natural processes [6 - 10].

The Yangiyul hydrometeorological station is located on the flat part of the basin, where anthropogenic pressure is significant compared to the mountainous territory. Agricultural irrigation is developed in this area, for which reliable hydrometeorological parameters play an important role in planning and managing water in irrigation.

Hydrometeorological station 4 is located near the Tuyabuguz reservoir. This territory is a transition zone from a mountainous landscape to a flat one; rainfed and irrigated agriculture is developed here. In rainfed agriculture, winter wheat and viticulture are mainly cultivated, the state of which is completely dependent on climatic factors, primarily on precipitation. Although hydrometeorological stations are located in the most characteristic areas of the basin with the corresponding radius of coverage, the methods of interpolation used do not allow to obtain reliable meteorological information, which is very necessary for a specific area of the basin.

The proposed method of interpolation of hydrometeorological data of territories is based on considering the basin territory as a system consisting of material points and in motion a single and whole in a single space. For such a system, the center is a material point that characterizes the movement of the whole system; for this research, these are the hydrometeorological parameters of the territory, concerning the problem under study, it is called the center of hydrometeorological parameters.

So other meteorological parameters, particularly air temperature, humidity, precipitation, etc., also by the elements of the system and their states change identically, as does the atmospheric pressure. To establish the center of the system or the center of the hydrometeorological parameters of the system, the meteorological station on the territory of Tashkent was taken as the beginning of accounting of the origin of coordinates (Fig. 1). 


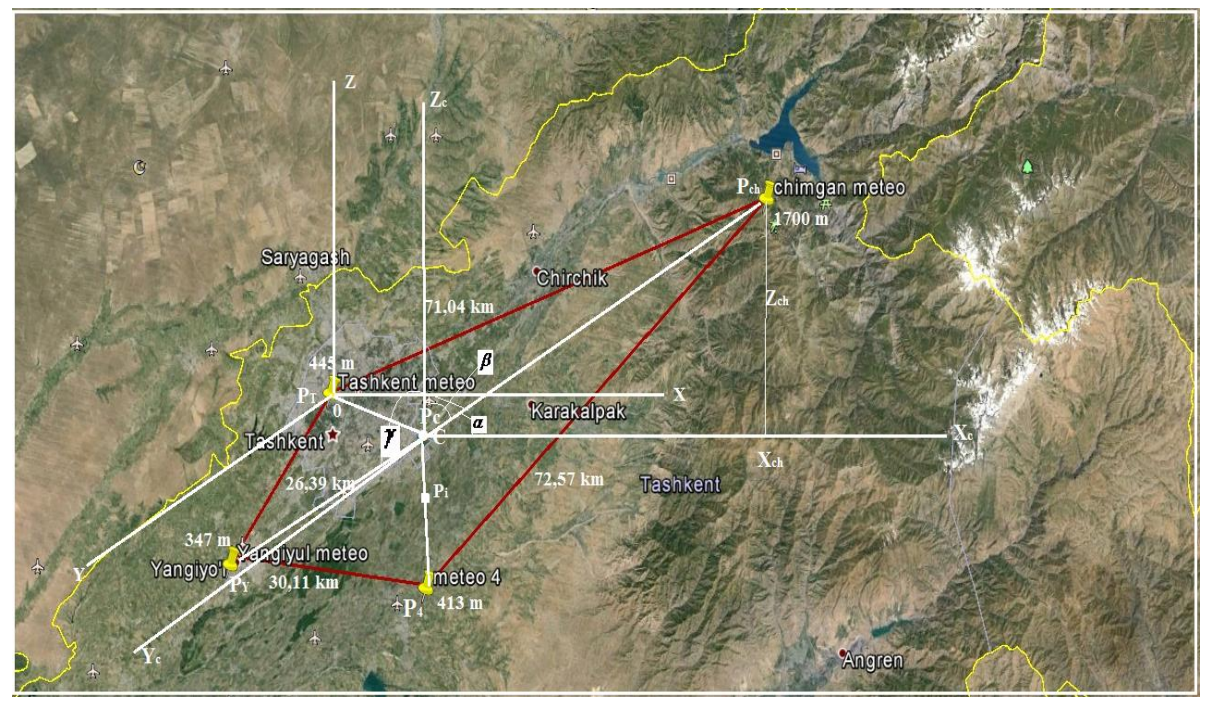

Fig. 1. Transferring the center of pressure for the study area. The figure shows $\vec{P}_{c} \vec{P}_{c h} ; \vec{P}_{c} \vec{P}_{T} ; \vec{P}_{c} \vec{P}_{Y} ; \vec{P}_{c} \vec{P}_{4}$ which are the pressure gradients

Similarly, the coordinates of the center of the other necessary for the hydrometeorological study parameters were established [1-5], [12, 13]:

- For atmospheric pressure, the value which depends on the altitude position of the territories, the coordinates of the center of pressure:

$$
x_{c}=\frac{1}{P} \sum p_{i} x_{i} ; \quad y_{c}=\frac{1}{P} \sum p_{i} y_{i} ; \quad z_{c}=\frac{1}{P} \sum p_{i} z_{i}
$$

where $P$ is the sum of monthly mean values of atmospheric pressure $\left(P_{i}\right)$ for 4 hydrometeorological stations

- $\quad$ For temperature $-\mathrm{T}^{0} \mathrm{C}$, center coordinates:

$$
x_{c}=\frac{1}{T} \sum_{i=1}^{i=4} T_{i} x_{i} y_{c}=\frac{1}{T} \sum_{i=1}^{i=4} T_{i} y_{i} z_{c}=\frac{1}{T} \sum_{i=1}^{i=4} T_{i} z_{i}
$$

where $\mathrm{T}$ is the sum of monthly average values of air temperature (Ti) for 4 hydrometeorological stations

- For atmospheric precipitation $\mathrm{O}$, center coordinates:

$$
x_{c}=\frac{1}{O} \sum O_{i} x_{i} ; y_{c}=\frac{1}{O} \sum O_{i} y_{i} ; \quad z_{c}=\frac{1}{O} \sum O_{i} z_{i}
$$

where $O$ is the sum of the mean monthly precipitation values $\left(O_{i}\right)$ for 4 hydrometeorological stations

- For air humidity, the coordinates of the center of humidity, where the humidity value is equal to its average value: 


$$
x_{c}=\frac{1}{B} \sum B_{i} x_{i} ; y_{c}=\frac{1}{B} \sum B_{i} y_{i} ; \quad z_{c}=\frac{1}{B} \sum B_{i} z_{i}
$$

where $B$ is the sum of monthly mean values of humidity $\left(B_{i}\right)$ for 4 hydrometeorological stations. $x_{i}, y_{i} z_{i}$ are coordinates of hydrometeorological stations relative to the origin of coordinates (Tashkent station).

The performed test calculations showed that the difference in meteorological parameters affects the position of their centers; each parameter: atmospheric pressure, precipitation, humidity, and temperature, etc., has its center. In this case, the variability of the values of meteorological parameters over time also affects the position of their centers.

In this regard, in the proposed method, for each meteorological parameter and for a certain point in time (when the measurements were made), it is necessary to make calculations using this technique separately. For example, the calculation results are given for two parameters: for atmospheric pressure and air humidity, respectively, for the monthly average data of two months of the different seasons of 2012.

For spatial interpolation of meteorological parameters, a parallel transfer of the coordinate system from the initial point "Tashkent meteo" to the center of mass-C was carried out. Parallel transfer of the coordinate system for air humidity is shown in Figure 2.

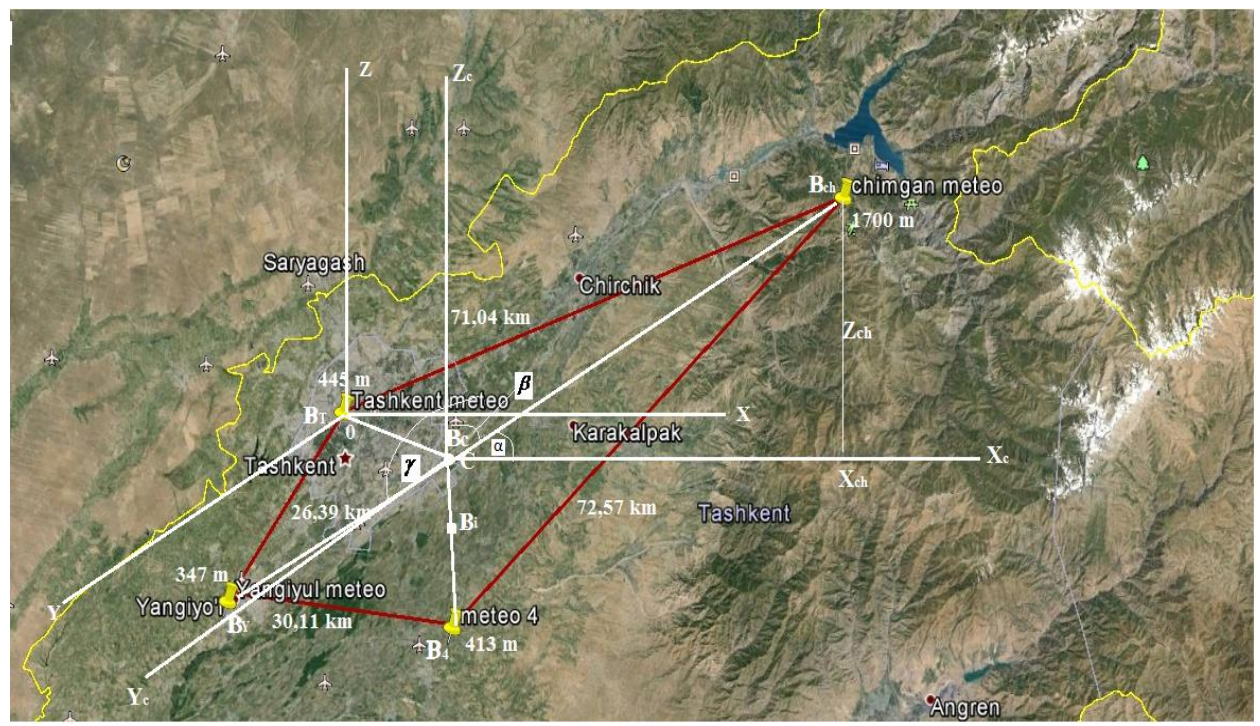

Fig. 2. Center of moisture and moisture gradients $\vec{B}_{c} \vec{B}_{c h} ; \vec{B}_{c} \vec{B}_{T} ; \vec{B}_{c} \vec{B}_{Y} ; \vec{B}_{c} \vec{B}_{4}$ (in \%) for the study area

The values of the coordinates of meteorological stations are calculated relative to the origin of coordinates $-\mathrm{C}$ and the corresponding monthly average value of meteorological parameters. In particular, the values of the coordinates of the meteorological station "Chimgan meteo" of atmospheric pressure (in meters) for the measured monthly mean values for February 2012 are equal to $\mathrm{P}_{\mathrm{ch}}(51766.49 ; 32088.03$; 1011.29).

Similarly, the values of coordinates of all meteorological stations on the territory of the Chirchik river basin are determined relative to the center of the humidity system. In particular, the coordinate of the Chimgan meteorological station relative to the center of humidity (system) of the territory (in meters) -point $\mathrm{B}_{\mathrm{c}}$ for the measured monthly average values of the test year for February 2012 is equal to $B_{\text {ch }}(55947.77 ; 35110.47 ; 1089.82)$. 


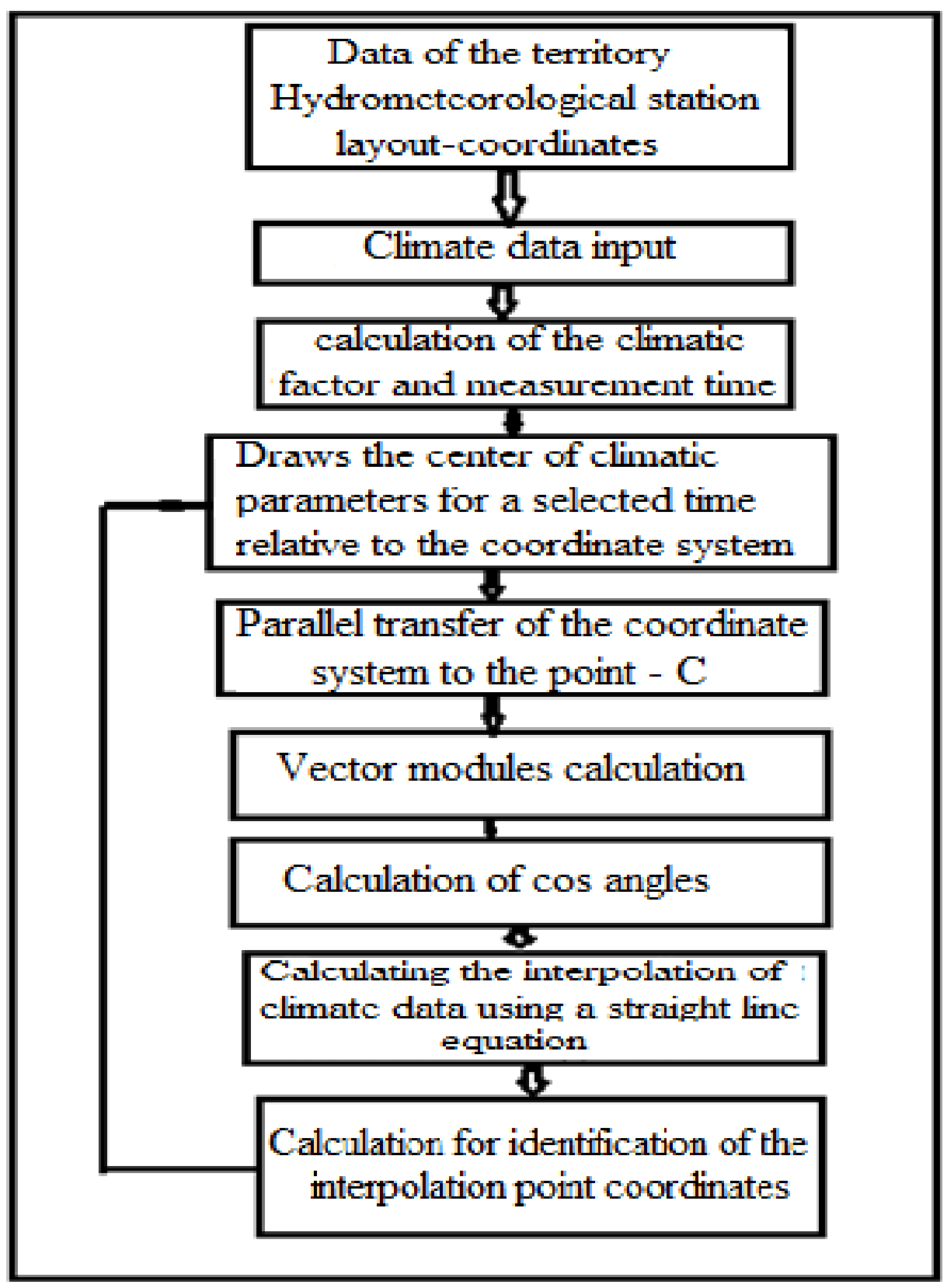

Fig. 3. Algorithm for calculation of interpolation method

\section{Results and Discussion}

The Chirchik River, the largest right tributary of the bank of the Syr Darya River, has a population of over 3.0 million dependents on sensitive water resources for nutrition. Water is supplied from five large deposits as well (about $45 \%$ of the internal consumption of Tashkent), numerous small deposits also from the water surface. Deteriorating water quality poses a serious threat to human health and the environment in the basin. There are no 
known viable alternatives to the resources of the Chirchik River Basin to provide drinking water to the residents of the Tashkent Region.

To analyze and assess the state of the water of the Chirchik River in the conditions of the river transformation through the territories in which there are large industrial enterprises and settlements: the cities of Gazalkent, Chirchik, Tashkent, etc. there is a need for ecological relationships between the river ecosystem and rather large urbanized areas. Monitoring methods traditionally used by hydrometeorological and environmental services do not contribute to tracking and assessing the dynamics of changes in the quantitative and qualitative parameters of river water.

In this regard, in the proposed interpolation method, it became necessary to create a combined system consisting of a landscape - a natural component and a system of material points - as a system representing a moving mass with a single center. In this case, the meteorological components of the territory are taken as elements of the mass system, which have their own centers of movement.

\section{Conclusions}

1. The proposed method with interpolation binding to the central reference point and using well-known and proven graphical-analytical approaches simplifies the calculation process and eliminates errors in establishing the estimated climatic parameters of the territory.

2. based on a computer program, an algorithm has been developed to produce interpolation by the proposed method.

3. According to the developed program, test calculations were performed, which confirmed the effectiveness of the proposed method for assessing the state of water bodies of sources for ecology and water supply of the population.

\section{References}

1. Zhuravlev V.F. Fundamentals of Theoretical Mechanics. 2nd ed. - M: Fizmatlit, - 320 p. (2001)

2. Baraev F.A., Muradov R.A., Khudaynazarov Zh.K., Turakhanov R.R., Makhmudov H.E. Program for optimizing the ratio of irrigated area and water supply. Computer program, Patent of the Republic of Uzbekistan DGU No. 01900, (2010)

3. Batralina, N. J. State of water resources in the East Kazakhstan region. Occupational health and medical ecology, 4, pp. 53-56, (2016)

4. Iskandarova, Sh. T. Forecast of changes in water quality in the Zeravshan river in the conditions of Uzbekistan Ecology and construction. M., 3. pp. 4-10. (2018).

5. Kurbanova, M. B. Ecological assessment of reservoirs in the middle reaches of the Syr Darya river basin Water resources, hydraulic structures and the environment: international collection. Conf. Baku. pp. 331-335. (2017).

6. Khasanova, M. I. On the issue of ecological safety of reservoirs in the middle reaches of the Syr Darya river basin. Journal "Ecological Bulletin Of Uzbekistan", 2, Tashkent. pp. 10-14.

7. Khasanova, M. I. About protection of reservoirs and drinking water use in Uzbekistan // journal "Ecology and construction", Moscow, 1. pp. 9-13. (2018).

8. Khodzhaeva, G. A., Musaeva, A. K. Ecological assessment of the state of reservoirs in the area where AGMK is located//in the collection of the international scientific and practical Internet conference "Modern ecological state of the natural environment and scientific and practical aspects of rational nature management", Russia. pp. 44-49, (2018). 
9. Makhmudov I.E., Musaeva A.K., Makhmudov Kh.E. Modern tasks of the development of centralized water supply systems in the city of Karshi, Theoretical foundations of medical and environmental problems in Uzbekistan and its practical solutions. Materials of the scientific-practical conference, T. 2009, pp. 36-37, (2009)

10. Makhmudov I.E. On the issue of the ecological state of reservoirs in the zone of influence of nonferrous metallurgy enterprises in Uzbekistan, Problems of water and land resources management: proceedings of the international conference. Conf. M., pp. 449-457. (2015).

11. Makhmudova D.E., Buriev E.S. Assessment Of Water Quality Of Small Rivers Of The Syrdarya Basins For The Safe Water Use// PalArch's Journal of Archaeology of Egypt/Egyptology, 17(7). pp. 9901-9910, (2020)

12. Usmanov I.A., Musaeva A.K., Makhmudov Kh.E. On the issue of improving hygienic monitoring of recreational water bodies, Materials of the 1st Republican Congress of Epidemiologists, Hygienists, Sanitary Physicians and Infectious Diseases, 11, pp. 31$32,(2010)$

13. Usmanov, I. A. Improving monitoring of water bodies in the middle course of the Syrdarya river basin. Current scientific and technical problems of habitat conservation: proceedings of the international conference. Conf. Brest, pp. 211-215. (2016).

14. Vasilieva, M. V. Influence of wastewater on water objects in the Voronezh region. The science, Thought, 7. pp. 34-39

15. Svintsov, A. P. Public water supply and rational use of water resources Vestnik RUDN, Engineering research series. 4. pp. 23-28. (2014).

16. Rakhimov Sh. Kh., Makhmudov E. Zh., Chen Shi, Abduvaili Jalili. Water resources and water use in Uzbekistan. Tashkent: Fan publishing House, 460 p. (2013).

17. Faizieva, D. H. Concept of justification of scientific works for the purpose of protection of water objects and providing the population with safe drinking water. Tashkent, 11, pp. 10-14. (2015) 